\title{
Interactive comment on "Moisture origin as a driver of temporal variabilities of the water vapour isotopic composition in the Lena River Delta, Siberia” by Jean-Louis Bonne et al.
}

\section{Anonymous Referee \#2}

Received and published: 2 March 2020

General comments: I believe that this paper is significant to see seasonal, synoptic variations of stable isotope ratios of vapor through 2-year collection of data. It is particular that it analyzes hydrological patterns by comparing not only with temperature and relative humidity, but also with wind directions, E-P and measured water vapor isotope ratio. Since characteristics of the study area are similar to those of polar regions, and it would be useful for studies of paleoclimate and modeling.

Specific comments:

135-138 Is there a comparison between IRMS and CRDS that measured stable isotope ratios of precipitation and vapor? Also, there is no clear explanation about the sampling 
method of rain.

185 The word 'interannual' is used only once in this sentence throughout the paper. This word seems unnecessary if there is no reason.

215 Positions of decimal points should be consistent throughout the paper.

255 It is hard to see the variations stated in ' 185 ' by using this figure. You should use the background color or grids.

314-315 There should be more details about why wind speed was used to verify the safety of synoptic situation.

343 The word 'reason' seems more reasonable that 'origin'

343 It would be better to write the equation even though it is general.

347 It is hard to see variations like '255'.

372 Why is there no exchange reaction in other seasons?

448 Is only the coldest month attributed to paleoclimate? There should be an explanation.

451 There should be an explanation on Verkhoyansk mountains in the introduction.

478-480 I recommend to add Figure 8.

503-504 Isn't it high and low extrema during Yellow Shade period? The description of the figure should be modified.

483-495 The order of the figure should be corrected. (a) would be the first. You should adjust the paragraph or the figures.

4.3.2 influence of the moisture source

Can the red area be seen as the moisture source because the moments measured (evaporation - precipitation) and stable isotope ratios of vapor are same? Also, long- 
distance transportation doesn't mean isotope distillation. You should consider that initial isotope ratios of vapor would be different regarding to the ocean temperature.

ACPD

Figure 5, 6, 9 Study area is denoted in green dots, but they are not clear. Azimuth should be indicated in the figure.

Interactive comment on Atmos. Chem. Phys. Discuss., https://doi.org/10.5194/acp-2019-942,

Interactive

comment 2020. 